\title{
Dreams and ability to recall: Comparison between propofol and ketamine in patients undergoing surgery under IVA
}

\author{
Lama Maya ${ }^{1}$, Sigdel Rohini ${ }^{1}$, Gurung Sanish ${ }^{1}$, Timilsina Sushil ${ }^{1}$ \\ ${ }^{1}$ Department of Anaesthesia, Pokhara Academy of Health Sciences, Western Regional Hospital
}

\section{Corresponding Author:}

Dr. Maya Lama,

Senior Consultant Anaesthesiologist

Department of Anaesthesia

Pokhara Academy of Health

Sciences,

Western Regional Hospital

Pokhara, Nepal

Email: maya_lama16@yahoo.com

Article received : February 11, 2018

Article accepted : March 11, 2018

\begin{abstract}
Background: Dreaming during anaesthesia is a common phenomenon. Dreams can occur with both inhalational agents as well as intravenous agents (IVA) like propofol and ketamine. But there are concerns like patient awareness, dreams and other untoward effects that may be associated with IVA. We have conducted this study to quantify the incidence of dreaming during IVA with propofol or ketamine. Methods: Sixty-nine patients aged 18 to 60 years scheduled for short procedures lasting from 5 to 25 minutes under IVA were randomized into two groups - group propofol or group ketamine. All the patients received midazolam and fentanyl intravenously. Then, patients in group propofol received propofol and those in ketamine group received ketamine for induction and maintenance of anaesthesia. After the end of surgery, when the patient were fully recovered from anaesthesia, patients were interviewed about occurrence of dreams and their ability to recall the dreams. Results: There were 35 patients in group propofol and 34 patients in group ketamine. The incidence of dreaming during anaesthesia was greater in patients of ketamine group, 23 (67.65\%), when compared to propofol group, $7(20 \%)(\mathrm{p}<0.001)$. Among the dreamers, 6 patients in the ketamine group and only 1 patient in the propofol group were able to recall their dream. Conclusion: Dreaming is quite common during IVA for short surgical procedure, more so following ketamine than propofol anaesthesia.
\end{abstract}

Key Words: Dreams; ketamine; propofol; intravenous anaesthesia

\section{INTRODUCTION}

Dreaming during anaesthesia is a common phenomenon but "why it occurs", "when it occurs" (its cause and timing) are poorly understood. ${ }^{1-5}$ The incidence of dreaming during anaesthesia varies between $0.5 \%$ to $38 \% .^{6-8}$ Dreams can occur with both inhalational agents as well as total intravenous agents. The incidence of dreaming following propofol anaesthesia is high. ${ }^{1-4 ; 9-10}$ The use of ketamine is also associated with emergence reactions including unpleasant dreams. ${ }^{11-13}$

The use of intravenous anaesthesia (IVA) is increasing in the past two decades. IVA is a type of general anaesthesia that is provided by using intravenous agents alone especially for short term surgery. The use of IVA is on the rise due to its several advantages like reduced incidence of postoperative nausea and vomiting (PONV) and reduced risk of air pollution inside the operation theatre when compared over the inhalational agents. But there are concerns like patient awareness, dreams and other untoward effects that may be associated with IVA. ${ }^{14}$

In a developing country like Nepal, the use of IVA for short surgical procedures is quite common. IVA is often achieved using drugs like propofol or ketamine along with midazolam and fentanyl. There are no studies in Nepal comparing the incidence of dreams during IVA with propofol vs ketamine. So, we have conducted this study to quantify the incidence of dreaming during IVA with propofol or ketamine. The use of drug with lesser incidence of dreams and associated emotions and feelings could be recommended for routine use.

\section{MATERIALS AND METHODS}

This was a single centred, prospective, double blinded, randomized trial. This study was carried out in the Operation Theatre and Post Anaesthetic Care Unit (PACU) of PAHS, WRH in the span of 4 months 10 
days. Our study was approved by the institutional review board.

After informed consents were obtained, sixty-nine patients were recruited in our study.

\section{PATIENT INCLUSION CRITERIA}

- Patients scheduled for short procedures lasting from 5 min to 25 min under IVA

- Age 18 years to 60 years

- American Society of Anaesthesiologists (ASA) I/II

\section{PATIENT EXCLUSION CRITERIA}

- $\quad$ ASA III or more

- Patients who were not able to communicate

The enrolled patients were randomly allocated to two groups, propofol group or ketamine group. Randomisation was done using sealed envelopes on the day of surgery. The surgeons, patient and the interviewer were blinded to group assignments. Intravenous anesthetic agents were administered to the patient by anesthesiologist.

\section{TREATMENT AND PROCEDURE}

Anxiety score and dream score of the patient was obtained before the start of surgery. $100 \mathrm{~mm}$ non-graduated visual analogue scale was used to obtain the preoperative anxiety score. The score ranged from 'not anxious at all' $(0 \mathrm{~mm})$ to 'very anxious' $(100 \mathrm{~mm}){ }^{3}$ Dream score of the patient was obtained by asking the patient how frequently he/she dreamt at home. Dream score was assigned as $0=$ 'never', 1 = 'once a month', 2 = 'once a week', 3 = 'every night'.

In the operation theatre, patient monitoring was done continuously using five lead electrocardiogram, pulse oximetry and standard blood pressure cuff. Oxygen was delivered to all the patients using simple face mask at the rate of 5 litres per minute.

All the patients received midazolam $0.02 \mathrm{mg} / \mathrm{kg}$ and fentanyl $1 \mathrm{mcg} / \mathrm{kg}$ intravenously. Patients in propofol group were given $2 \mathrm{mg} / \mathrm{kg}$ of propofol for induction and $1 \mathrm{mg} / \mathrm{kg}$ as needed every 3-5 minutes for maintenance. Patients in ketamine group received $1 \mathrm{mg} / \mathrm{kg}$ ketamine for induction and maintenance was done with $0.5 \mathrm{mg} / \mathrm{kg}$ as needed every 5-10 minutes.

After induction, airway was maintained using head tilt, chin lift and jaw thrust technique as required. Equipments necessary for advanced airway management were kept ready.
At the end of surgery, patients were transferred to the recovery room and observed till full recovery. When the patients were fully conscious and oriented to time, place and person, the blinded interviewer interviewed the patient and completed the form about dreaming and various emotional states and feelings. The answers to these questions were 'Yes' or 'No'. Patients were asked if they had any dreams or images during IVA and if yes, whether they were able to recall the dream or not. Patients were also asked whether they were angry, apprehensive, happy, sad or confused (the five feelings present on the Hall \& van der Castle emotions scale). ${ }^{15}$ The validity and reliability of the emotions scale has been documented by Winget \& Kramer. ${ }^{16}$ Patients were also enquired about whether they were sick, hungry, high, sedated, dizzy, light hearted (six bodily and biological states derived from the work of Zacny et al..). ${ }^{17}$ We also asked the patients if they had 'headache' and if they were 'thirsty'.

\section{OUTCOMES}

The primary endpoint of our study was the incidence of dreaming during IVA and ability to recall the dream. The secondary endpoints were the various feelings and emotional states.

\section{STATISTICAL ANALYSIS}

We calculated that if $35.71 \%$ patients dreamt during anaesthesia, at an alpha value of $5 \%$ and a beta value of $80 \%$, a sample size of 34 patients were required in each group. Data were analyzed using SPSS version 20.0 (SPSS, Chicago, IL, USA). Comparison between two groups was done using independent t-test or MannWhitney U-test and categorical data were compared using Chi-square test or Fisher's exact test wherever appropriate. $\mathrm{P}<0.05$ was considered to be statistically significant. Bonferroni's correction was applied to correct for repeated observations in the emotion and body status questionnaire; with 13 related questions a probability value of less than 0.0038 was taken as significant.

\section{RESULTS}

A total of 69 patients were included in our study, (Table I) out of which 35 patients received propofol anaesthesia and 34 received ketamine anaesthesia. 
Table I: Types of surgery

\begin{tabular}{lclc}
\hline Type of surgery & No. & Type of surgery & No. \\
\hline Manual vacuum aspiration & 39 & Excision of fibroadenoma of breast & 3 \\
Cervical polypectomy & 9 & Incision and drainage of breast abscess & 1 \\
Endometrial biopsy & 8 & Auricular dermoid excision & 1 \\
Dilatation and curettage & 2 & Incision and drainage of left shin abscess & 1 \\
Marsupialization of bartholin cyst & 2 & Debridement of crush injury of foot & 1 \\
CuT removal & 1 & Debridment of infected wound & 1 \\
\hline
\end{tabular}

There was no significant difference in age, sex distribution, preoperative anxiety and dream score between the two groups. (Table II)

\section{Table II: Patient Characteristics}

\begin{tabular}{lccc}
\hline & Propofol group $(\mathbf{n = 3 5})$ & Ketamine group $(\mathbf{n = 3 4})$ & p-value \\
\hline Age (years) & $30(18,53)$ & $29.5(16,48)$ & 0.362 \\
Gender & & 1 & \\
Male & 3 & 33 & 0.614 \\
Female & 32 & $45(0,100)$ & \\
Anxiety Score & $30(0,100)$ & $2(0,3)$ & 0.380 \\
Dream Score & $2(1,3)$ & & 0.225 \\
\hline
\end{tabular}

The total duration of anaesthesia was similar in the two groups. (Table III)

\section{Table III: Duration of anaesthesia}

\begin{tabular}{lccc}
\hline & Propofol group $(\mathbf{n}=35)$ & Ketamine group $(\mathbf{n}=34)$ & p-value \\
\hline $\begin{array}{l}\text { Total duration } \\
\text { (minutes })\end{array}$ & $15.71 \pm 4.482$ & $15.53 \pm 4.294$ & 0.862 \\
Data given as mean \pm SD & & & \\
\hline
\end{tabular}

The incidence of dreaming during anaesthesia was significantly greater in patients of ketamine group, 23 (67.65\%), when compared to propofol group, $7(20 \%)$, ( $p<0.001)$. The total number of dreams with recall as well as dreams without recall were both higher in the ketamine group compared to the propofol group but these were statistically not significant $(\mathrm{p}=0.215)$. (Figure 1$)$ 


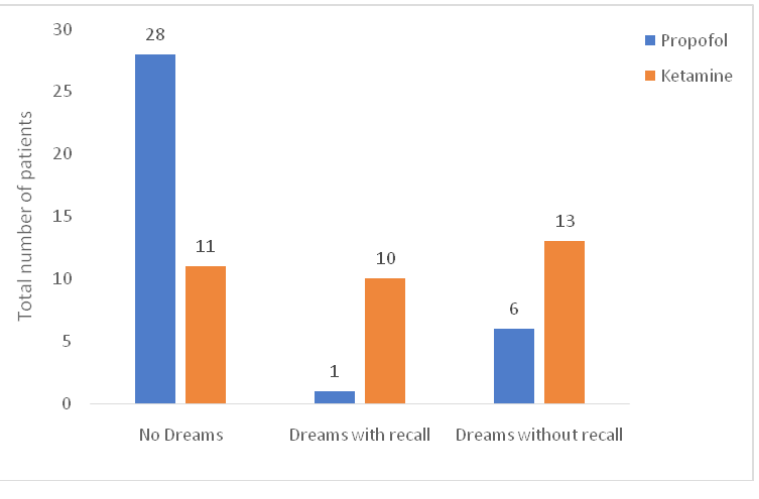

Figure 1: Incidence of dreaming during anaesthesia

Patients in ketamine group reported significantly higher incidence of feeling 'high' $(p=0.001)$ and 'dizzy' ( $p=$ 0.003 ). The occurrence of other feelings and emotional states are shown in Table IV.

Table IV: Total number of patients reporting various Feelings and Emotional States

\begin{tabular}{lccc}
\hline & $\begin{array}{c}\text { Propofol group } \\
(\mathbf{n = 3 5})\end{array}$ & $\begin{array}{c}\text { Ketamine group } \\
(\mathbf{n = 3 4})\end{array}$ & \\
\hline Angry & 0 & 0 & \\
\hline Happy & 4 & 7 & 0.342 \\
Sad & 26 & 22 & 0.440 \\
\hline Confused & 5 & 7 & 0.540 \\
\hline Sick & 23 & 24 & 0.797 \\
Hungry & 10 & 21 & 0.008 \\
\hline High & 11 & 15 & 0.326 \\
\hline Sedated & 20 & 22 & $0.001 *$ \\
Dizzy & 14 & 26 & 0.126 \\
Light earted & 23 & 26 & $0.003 *$ \\
Headache & 4 & 20 & 0.624 \\
Thirsty & 19 & 13 & 0.013 \\
Data represented as n & 20 & 0.809 \\
$*$ P $<0.0038$ between groups & & \\
\hline
\end{tabular}

\section{DISCUSSION}

In our study, we found that the incidence of dreaming following ketamine anaesthesia is about $67.65 \%$ and following propofol anaesthesia is $20 \%$ in patients who received IVA for short surgical procedures. The incidence of dreams following administration of propofol was comparable to previous studies, 2, 9-10 whereas the incidence following ketamine administration was higher than previous studies. ${ }^{18-19}$
Hellwagner et al. found that the incidence of dreaming during propofol anaesthesia was $40 \%{ }^{2}$ Stait et al. reported dreaming in $25.5 \%$ of patients who underwent elective colonoscopy under intravenous sedation with propofol, midazolam and fentanyl. ${ }^{9}$ Audrey et al. had found that the incidence of dreaming was $19 \%$ in patients sedated with combinations of propofol, midazolam and fentanyl during elective outpatient colonoscopy. ${ }^{10}$ The incidence of unpleasant dreams ranged from $11 \%-53 \%$ in patients administered with ketamine. ${ }^{18-19}$

Blagrove et al. had shown that there was no significant difference in the dream recall frequency among healthy volunteers over the three nights after receiving subanaesthetic dose of ketamine or placebo. ${ }^{18}$ In our study also, there was no significant difference in the ability to recall dreams among dreamers of propofol and ketamine group.

Few studies have shown that the incidence of dreams during ketamine anaesthesia was high among homedreamers ('defined as those patients who ordinarily dream at home') compared to non-home-dreamers. ${ }^{19-20}$ In our study, $95.7 \%$ of the dreamers in ketamine group were home-dreamers ('defined as those patients who dreamt at home either daily or once a week or once a month'). There was only one patient in our study (ketamine group) who was a non-home-dreamer. She also reported of dreaming during anaesthesia. A study had shown that the incidence of dreaming during sedation with propofol was higher among home-dreamers. ${ }^{19}$ In our study; all the patients who reported dreaming with propofol anaesthesia were homedreamers.

There are conflicting reports regarding whether dreams during anaesthesia are distressing to the patients or not. Some studies suggest that dreaming during anaesthesia is sometimes distressing to patients and may decrease satisfaction with care. ${ }^{6}$ Other studies have shown that most of these dreams are pleasant and patient satisfaction and quality of anaesthesia is not affected by these dreams. ${ }^{1-2}$, $4,5,21$

The co-use of other drugs during anaesthesia, e.g. benzodiazepines, ${ }^{22}$ clonidine, ${ }^{23}$ can reduce the incidence of unpleasant dreams associated with ketamine. ${ }^{18}$ So, the use of drugs like midazolam should be encouraged during IVA with ketamine.

Our study had some limitations. Dreaming and recall are subjective phenomena. Some patients may not have considered their experience to be dreaming and may not have reported their experience. We didn't monitor the depth of anaesthesia during surgery using bispectral index (BIS). 


\section{CONCLUSION}

Dreaming is quite common during IVA for short surgical procedure, more so following ketamine than propofol anaesthesia. So, propofol may be used routinely for IVA for short surgical procedures.

\section{REFERENCES}

1. Leslie K, Skrzypek H, Paech MJ, Kurowski I, Whybrow T. Dreaming during anesthesia and anesthetic depth in elective surgery patients: a prospective cohort study. Anesthesiology. 2007 Jan;106(1):33-42.

2. Hellwagner K, Holzer A, Gustorff B, Schroegendorfer K, Greher $\mathrm{M}$, Weindlmayr-Goettel M, et al. Recollection of dreams after short general anaesthesia: influence on patient anxiety and satisfaction. Eur J Anaesthesiol. 2003;20(4):282-8.

3. Brandner B, Blagrove M, McCallum G, Bromley LM. Dreams, images and emotions associated with propofol anaesthesia. Anaesthesia. 1997 Aug;52(8):750-5.

4. Kasmacher H, Petermeyer M, Decker C. [Incidence and quality of dreaming during anesthesia with propofol in comparison with enflurane]. Anaesthesist. $1996 \mathrm{Feb}$;5(2):146-53.

5. Errando CL, Sigl JC, Robles M, Calabuig E, Garcia J, Arocas $\mathrm{F}$, et al. Awareness with recall during general anaesthesia: a prospective observational evaluation of 4001 patients. $\mathrm{Br} \mathrm{J}$ Anaesth. 2008 Aug;101(2):178-85.

6. Leslie K, Myles PS, Forbes A, Chan MT V, Swallow SK, Short TG. Dreaming during anaesthesia in patients at high risk of awareness. Anaesthesia. 2005 Mar;60(3):239-44.

7. Myles PS, Leslie K, McNeil J, Forbes A, Chan MT V. Bispectral index monitoring to prevent awareness during anaesthesia: the B-Aware randomised controlled trial. Lancet (London, England). 2004 May;363(9423):1757-63.

8. Sebel PS, Bowdle TA, Ghoneim MM, Rampil IJ, Padilla RE, Gan TJ, et al. The incidence of awareness during anesthesia: a multicenter United States study. Anesth Analg. 2004 Sep;99(3):833-9.

9. Stait ML, Leslie K, Bailey R. Dreaming and recall during sedation for colonoscopy. Anaesth Intensive Care. 2008 Sep;36(5):685-90.

10. Eer AS, Padmanabhan U, Leslie K. Propofol dose and incidence of dreaming during sedation. Eur J Anaesthesiol. 2009 Oct;26(10):833-6.

11. Vinnik CA. Dissociative anesthesia in an office-based plastic surgery practice. Semin Plast Surg. 2007 May;21(2):109-14.

\section{ACKNOWLEDGEMENT}

We are grateful to all the doctors of Department of Anaesthesiology, anaesthesia assistants, nursing and others staffs of operation theatre of PAHS for their contribution in completion of this research.
12. Sarasso S, Boly M, Napolitani M, Gosseries O, Charland-Verville $\mathrm{V}$, Casarotto $\mathrm{S}$, et al. Consciousness and Complexity during Unresponsiveness Induced by Propofol, Xenon, and Ketamine. Curr Biol. 2015 Dec;25(23):3099-105.

13. Cheong SH, Lee KM, Lim SH, Cho KR, Kim MH, Ko MJ, et al. Brief report: the effect of suggestion on unpleasant dreams induced by ketamine administration. Anesth Analg. 2011 May;112(5):1082-5.

14. Miller TE, Gan TJ. Total intravenous anesthesia and anesthetic outcomes. J Cardiothorac Vasc Anesth. 2015 Jun;29 Suppl 1:S115 .

15. Hall CS, Van de Castle RL. The content analysis of dreams [by] Calvin S. Hall and Robert L. Van de Castle. New York: AppletonCentury-Crofts; 1966.

16. Winget C. KM. Dimensions of Dreams. Univ Florida Press. 1979;

17. Zacny JP, Lichtor JL, Coalson DW, Finn RS, Uitvlugt AM, Glosten B, et al. Subjective and psychomotor effects of subanesthetic doses of propofol in healthy volunteers. Anesthesiology. 1992 May;76(5):696-702.

18. Blagrove M, Morgan CJA, Curran HV, Bromley L, Brandner B. The incidence of unpleasant dreams after sub-anaesthetic ketamine. Psychopharmacology (Berl). 2009 Mar;203(1):109-20.

19. Hejja P, Galloon S. A consideration of ketamine dreams. Can Anaesth Soc J. 1975 Jan;22(1):100-5.

20. White PF, Way WL, Trevor AJ. Ketamine--its pharmacology and therapeutic uses. Anesthesiology. 1982 Feb;56(2):119-36.

21. Leslie K, Skrzypek H. Dreaming during anaesthesia in adult patients. Best Pract Res Clin Anaesthesiol. 2007 Sep;21(3):40314.

22. Grace RF. The effect of variable-dose diazepam on dreaming and emergence phenomena in 400 cases of ketamine-fentanyl anaesthesia. Anaesthesia. 2003 Sep;58(9):904-10.

23. Handa F, Tanaka M, Nishikawa T, Toyooka H. Effects of oral clonidine premedication on side effects of intravenous ketamine anesthesia: a randomized, double-blind, placebo-controlled study. J Clin Anesth. 2000 Feb;12(1):19-24. 